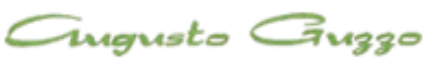

REVISTA ACADEMICA

\title{
Gerenciamento do conhecimento: origem, contexto histórico e gestão
}

\author{
Roberto Regensteiner ${ }^{1}$ \\ Recebido em: 12/10/2013. Aprovado em: 12/11/2013. Disponibilizado em: 20/12/2013
}

1. Mestre em Economia e Sistema da Informação Professor universitário, Pesquisador, Parecerista e avaliador de trabalhos de Revistas Acadêmicas. Orientador de trabalhos de conclusão de curso de Graduação e Pós-graduação em Economia e Sistema de Informação

\section{Resumo}

A expressão Knowledge Management (KM ou Gerenciamento do Conhecimento) passou a circular amplamente, em meados da década de 1980, a partir de sua utilização no livro de Nonaka e Takeuchi (1997) e graças a um contexto em que as corporações industriais japonesas conquistavam expressivas fatias de mercado a expensas de seus concorrentes dos EUA e de outras partes do mundo. A superioridade das empresas japonesas sobre suas concorrentes foi atribuída à sua maior capacidade de Gerenciar o Conhecimento. Este artigo destaca os principais aspectos do livro e critica seus pontos fracos. Identifica na realidade as questões que dão relevância aos conceitos abordados. Mostra como o Gerenciamento de Conhecimento se constituiu em área de pesquisa acadêmico-corporativa ao incorporar ao seu campo de estudo temas ligados a Tecnologia da Informação (como a colaboração, a gestão documental, o ensino à distância e o data mining, entre outros) e a "Propriedade Intelectual".

Palavras-chave: Knowledge Management; Gerenciamento do Conhecimento; Propriedade Intelectual.

\begin{abstract}
The term Knowledge Management began to circulate widely in the mid-1980s, from its use in the book of Nonaka and Takeuchi (1997) and thanks to a context where Japanese industrial corporations conquered expressive market share at the expense of their competitors in the U.S. and other parts of the world. The superiority of the Japanese over their competitors was attributed to its greater ability to manage knowledge. This article highlights the main aspects of the book and criticizes its weaknesses, points the issues in reality that gave relevance to the concepts and shows how the integration to the KM field of subjects related to Information Technology (such as collaboration, document management, distance learning and data mining, among others) and "Intellectual Property" led Knowledge Management to become an area of academic and corporate research.
\end{abstract}

Keywords: Knowledge Management; Intellectual Property 


\section{Introdução}

Conhecimento e gestão são termos que, separadamente, estão em circulação há muito tempo. Neste texto ressaltam-se aspectos históricos relevantes que integram a expressão: Gestão do conhecimento (GC) [ou do original, em inglês, Knowledege management $(\mathrm{KM})]$. No novo milênio a gestão do conhecimento passou a ser considerado um divisor de águas, a partir do momento em que a expressão e o conceito de Knowledege Management se definiu como uma área de estudos, pesquisas no contexto acadêmico, corporativo e econômico. $\mathrm{O}$ termo foi colocado em evidência, foram exploradas as suas raízes e o contexto histórico e passou a integrar as temáticas relacionadas a um novo campo de estudos, a Tecnologia da Informação e "Propriedade Intelectual", correlacionadas aos processos de inovação.

A partir da publicação do livro "The Knowledge-Creating Company: How Japanese Companies Create the Dynamics of Innovation" (Nonaka e Takeuchi, 1995) a expressão Gerenciamento do Conhecimento passou a circular com novas amplitudes e densidades.

A abordagem trata-se de um viés acadêmico estadounidense, tanto pela forma, como pelo conteúdo. A obra foi publicada em 1986, foi redigida para atender a um pedido de professor tornam Business School. Ela explica as singularidades das empresas japonesas e o que fazem a serem tão bem sucedidas. Cabe assinalar aqui para retomarmos adiante que, em meados da década de 1980, quando foi feito o pedido, a

${ }^{1}$ Conforme o Houaiss (2009) há registros do uso do termo conhecimento desde o século XII e do termo gestão desde o século XIX. Esta antiguidade etimológica dos termos em português se aplica, também, à língua inglesa de onde os mesmos nos chegaram na atualidade. penetração da indústria e da produção (em especial a de automóveis) japonesa no mercado dos EUA tornava-a o bode expiatório de uma série de problemas econômicos vividos por aquele país.

Como na maior parte das produções acadêmicas, o primeiro capítulo é uma Introdução que apresenta o plano da obra e suas principais conclusões. $\mathrm{O}$ segundo capítulo é uma ambiciosíssima revisão de vários conceitos como Inovação, Knowledge e Management desde as vertentes da Filosofia Ocidental (vai de Platão e Aristóteles até o século XIX, com destaque para Descartes) e Japonesa (budismo, confucionismo) à luz das Teorias Econômica e Administrativa. Tudo isto é contrastado e o resultado sintetizado em menos de 40 páginas onde se conclui pela Necessidade da Teoria da Criação do Conhecimento Organizacional à qual será dedicado o restante do trabalho ${ }^{2}$.

Teoria da Criação do Conhecimento Organizacional é o título do terceiro capítulo e que, tomado individualmente, talvez tenha sido o que mais atenção obteve no mundo acadêmico. Nele os autores desenvolveram a diferenciação entre dois aspectos do Conhecimento: os tácitos (aqueles mais individuais, subjetivos, disponíveis na memória dos participantes e compartilhados de modo mais informal e voluntário) e os explícitos (mais formais e objetivados em normas, manuais, softwares) e descrevem uma espiral de conversão de um aspecto em outro, fundamentando-se em diversos casos extraídos da história de grandes empresas, em sua maioria japonesas. Estes processos foram por eles sintetizados na imagem a seguir que podemos denominar de Modelo SECI (pelo uso das letras iniciais de Socialização,

\footnotetext{
${ }^{2}$ Com todo o devido respeito que os autores nos merecem e a despeito das evidências do conhecimento que possam ter dos temas tratados, este capítulo é apenas uma tentativa ainda superficial de integrar temáticas controversas.
} 
Externalização, Combinação e Internalização, que seriam as fases e processos percorridos pela Espiral do Conhecimento). Este Modelo será usado no decorrer do livro para comparar processos entre diferentes empresas e culturas.
O Modelo SECI da Espiral do Conhecimento explica a ordem e a evolução da Socialização, Externalização, Combinação e Internalização.

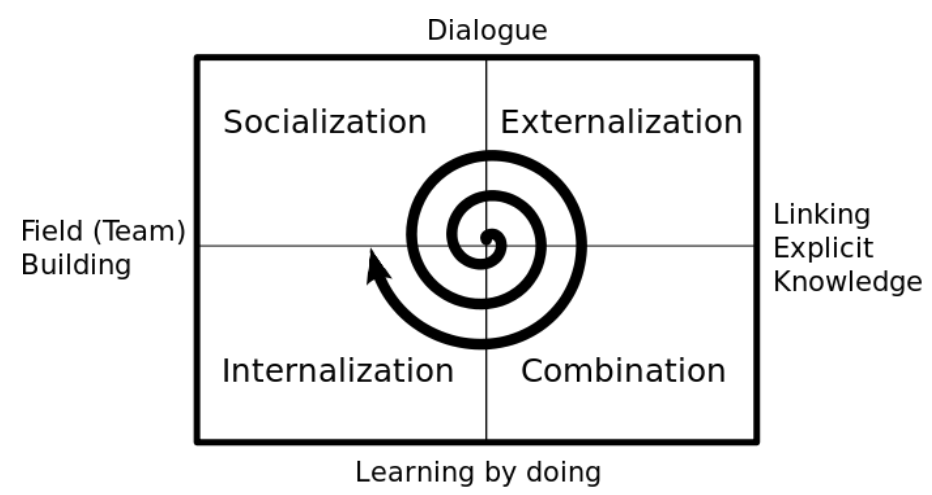

Fonte da imagem: Nonaka, 1995.

A criação do conhecimento na prática é o título do quarto capítulo um dos mais interessantes e saborosos do livro. Apresenta o processo que resultou na máquina doméstica de fazer pão (a Home Bakery), lançado pela Matsushita no mercado japonês em 1987, com sucesso comercial. Apresenta com riqueza de detalhes desde o levantamento das condições de mercado para aquele produto até o background dos membros da equipe de desenvolvimento, passando pelo modo como foi sendo especificado o produto. O ponto culminante - quase épico - ressalta como a equipe conseguiu integrar ao protótipo o que parecia ser quase impossível: habilidades manuais, táteis, sensoriais e outras dos padeirosartesãos. "Se o artesão não pode explicar suas habilidades, então os engenheiros devem transformar-se em artesãos" (Nonaka, 1997, p.116). O relato da interação entre a equipe encarregada da inovação e os detentores do conhecimento e das habilidades que se deseja automatizar é inspirador a todos quantos se proponham a trabalhar com automação e inovação. Os autores usam o caso desta máquina e seus impactos posteriores na
Matsushita para dar concretude a aspectos teóricos e aos modelos que sustentam a sua formulação da espiral do conhecimento.

O "Processo Gerencial Middle-up-down para a Criação de Conhecimento" aborda e defende o modelo gerencial japonês, mais adequado à criação de conhecimento e no qual gerentes intermediários desempenham os papéis mais relevantes do processo. É usado como estudo de caso, o exemplo da Canon e o interessantíssimo processo de invenção do cartucho descartável contendo o tonner que possibilitou a gigantesca ampliação do mercado de copiadoras antes restritas aos grandes usuários. Este modelo middle-up-down é apresentado como uma inovação organizacional que aliaria as vantagens dos modelos Top-down (exemplificado em sua dimensão teórica com o que supostamente foi proposto por Taylor e Weber e concretizado com abundância de exemplos retirados da gestão da GE sob o comando do celebérrimo Jack Welch) e Bottom-up (que seria o inverso do top-down: horizontalizado, com poucos níveis hierárquicos, autonomia para a base $\mathrm{da}$ 
pirâmide e assim por diante, exemplificado pelo caso da $3 \mathrm{M}$, sempre celebrada pela capacidade inventiva e por sua diretriz de obter parte significativa de suas receitas com produtos inovadores lançados recentemente).

Ao final do capítulo os autores ensaiam uma estruturação de perfis de membros do que poderia vir a ser uma Equipe de Criação do Conhecimento, que seria composta por: (i) profissionais (funcionários de linha de frente e gerentes operacionais); (ii) engenheiros do conhecimento (gerentes de nível médio) e (iii) gerentes do conhecimento (alta direção).

No afã de generalizar para outras empresas e países (e, seja dito, com a embocadura característica do marketing dos EUA que busca "vender" idéias e receitas que possam gerar receita $\$ 3$ ) o livro apresenta três interessantes capítulos que finalizam a obra. Quando o autor explica "a Nova Estrutura Organizacional" define organização o "hipertexto" como uma estrutura organizacional que permitiria a criação e a exploração de conhecimento de forma eficaz, repetida e contínua, com as virtudes e sem os males da burocracia ou da força-tarefa. Defendem que seja feita uma síntese de ambos os tipos. O Exército dos EUA é apresentado como exemplo desta síntese, pois seria estruturado de modo burocrático em tempos de paz e como força-tarefa nos períodos de guerra. Há uma interessante digressão na qual são ressaltados os aspectos organizacionais relevantes que no decorrer $\mathrm{da}$ 2.a Guerra Mundial teria levado este Exército à vitória sobre o burocratizado Exército Imperial Japonês. Finalmente, há um esforço de exemplificação e de teorização do que seria a organização em hipertexto usando os casos das empresas japonesas Kao (empresa "em transição" para a estruturação em hipertexto)

\footnotetext{
${ }^{3}$ Nonaka, 1995, no capítulo 8, p. 261: apresenta as implicações práticas para os profissionais de negócios
}

e Sharp (organização em hipertexto "aperfeiçoada").

Em "Criação do Conhecimento Organizacional Global" discutem as possibilidades de o processo de criação do conhecimento organizacional funcionar fora do Japão e quais os ajustes que precisariam ser feitos para que isto ocorra. Fazem uma análise comparativa da mecânica de criação do conhecimento na organização japonesa e na "ocidental" usando o Modelo SECI e apoiado nos casos bem-sucedidos de desenvolvimento de dois produtos: o primeiro carro global da Nissan e as escavadeiras da joint-venture nipo-americana Caterpillar Mitsubishi. São relatos extraordinariamente instrutivos que colocam em evidência características culturais e operacionais das citadas empresas japonesas e que dão utilidade e ilustram o Modelo SECI anteriormente apresentado. $\mathrm{O}$ autor sumariza a teoria e discute a receita para sua universalização.

\section{Avaliação Crítica}

Nonaka focalizar a criação e disseminação de conhecimento em estreita relação com os ricos casos concretos reportados de desenvolvimento de novos produtos por algumas grandes corporações do Japão e dos EUA. O Modelo SECI (Socialização, Externalização, Combinação e Internalização) é uma contribuição relevante que parece ter tido boa acolhida nos meios acadêmicos e corporativos interessados no assunto. Por meio dele se busca entender e descrever os processos integrando indivíduos e grupos na espiral em que se sucedem as transformações dos aspectos tácitos em explícitos do conhecimento. Não obstante, a receptividade do texto parece decrescer com a amplitude das generalizações que o livro

interessados em implementar um programa...dentro de suas empresas. 
apresenta, seja quando propõe um conjunto de passos a serem seguidos por quem queira sistematizar práticas de GC para conduzir as corporações a uma forma hipertextual ${ }^{4}$ de organização, seja quando tenta desenvolver uma síntese multidisciplinar de aspectos científicos relevante. $O$ livro segue cumprindo um papel positivo ao chamar a atenção para a questão do conhecimento, e dos processos envolvidos em sua criação e transmissão evidenciando sua importância em relação à inovação.

O livro pode reivindicar o papel de importante catalisador na estruturação da GC como um novo campo de estudos, pois, de fato, é a partir de 1995 que cresce muito o uso da expressão Gerenciamento do Conhecimento, surgem journals e sociedades academico-científicas nos EUA e em outras partes refletindo um crescente interesse no assunto. No Brasil, a SBGC (Sociedade Brasileira de Gestão do Conhecimento, www.sbgc.org.br) foi constituída em 2001.

Entretanto, mesmo reconhecendo os importantes méritos desta publicação é descabido afirmar que o livro define a origem do assunto Knowledege -. Já em 1991 Nonaka publicara um artigo ${ }^{5} \mathrm{com}$ este tema no título. Além disto, há outros notáveis antecedentes sem que por isto a GC tenha se

${ }^{4}$ Nonaka em entrevista em Nov-2011 sobre o assunto não menciona nenhuma organização que concretize o conceito de organização hipertextual (v. http://www.slideshare.net/jonker1/hypertextorganization-ikujiro-nonaka-interview). Tampouco na bibliografia a que tivemos acesso verifica-se uma aceitação significativa deste paradigma. constituído como campo acadêmico, nem se transformado em alvo de tanto interesse. Veja-se, por exemplo, a invenção do termo e uma primeira conceituação do que seja a sociedade da informação ${ }^{6}$ que é atribuída a Fritz Machlup em seu livro "The Production and Distribution of Knowledge in the United States" (1962). Ou, ainda mais remotamente, em 1959, o célebre Peter Drucker levantara o tema do knowledge worker (trabalhador do conhecimento) $)^{7}$ sem que isto tenha tido na época maiores repercussões.

Podem observar, portanto, que se o assunto abordado no livro de 1995 não se constituiu, propriamente, em uma novidade, devendo buscar as razões para exercer este papel catalisador nos processos históricos e nos contextos subjacentes.

Como se evidencia o interesse original que suscitou o livro foi a busca de entendimento das singularidades das empresas japonesas. Vejamos agora as razões desta "curiosidade". Gerenciamento do Conhecimento no Contexto Histórico Origem do interesse nas empresas japonesas.

Uma das tiras de www.Dilbert.com evidenciando que a referida circularidade simbiótica corporação-academia-indústria editorial do fenômeno contemporâneo:

\footnotetext{
5 Nonaka, I. The Knowledge-Creating Company. http://hbr.org/2007/07/the-knowledge-creatingcompany/es

${ }^{6}$ Machlup, F..The Production and Distribution of Knowledge in the United States, 1962

7 Drucker, Peter (1957). Landmarks of Tomorrow. New York: Harper \& Row. p. 122. ISBN 978-156000-622-0., citado em http://en.wikipedia.org/wiki/Peter_Drucker.
} 


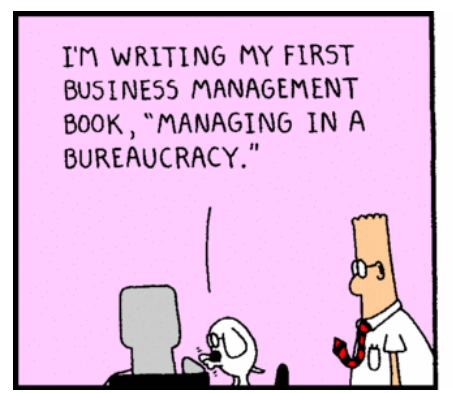

Gráfico elaborado pelo autor com dados baixados do Google Trends em 30/8/2013
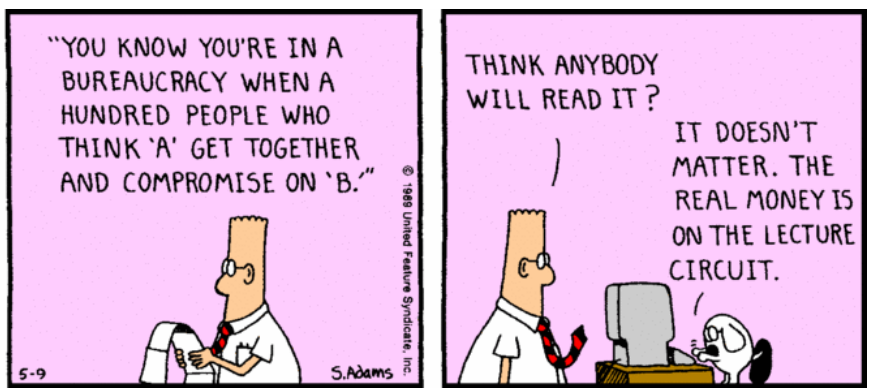

para consultas com o termo "Knowledge Management”: entre 2004 e 2013

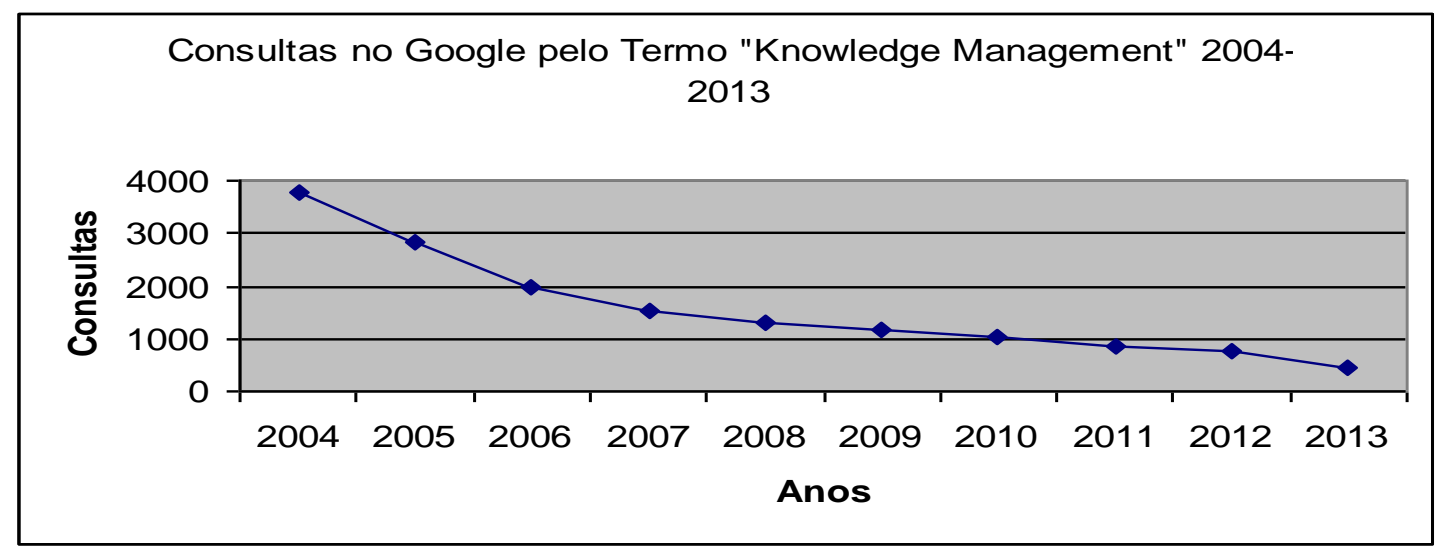

Depois da 2.a Guerra Mundial o Japão precisou reconstruir-se e teve início um riquíssimo processo de criação e inovação de produtos e métodos de produção. $\mathrm{O}$ resultado obtido inclusive com a colaboração de consultores trazidos do exterior incorporou as características próprias de uma ilha carente de matérias primas, que valoriza detalhes e busca a economia de custos, sem mencionar grande número de aspectos que ainda precisam ser devidamente estudados e compreendidos. Assim, quando sucessivamente em 1973 e 1979, os preços internacionais do petróleo triplicaram, a indústria japonesa, e em especial seu setor automobilístico, encontrou condições favoráveis para penetrar fortemente no maior mercado do mundo que era o dos EUA. Isto abalou o cluster da indústria automobilística

${ }^{8}$ Abordei a questão dos métodos de produção mais eficientes e uma cultura menos propensa ao desperdício em meu trabalho sobre "As Modas na Administração...”. Para conhecer em detalhes as (montadoras, autopeças, revendedores, transportadores, prestadores de serviços e assim por diante). Conforme aumentavam o preço da gasolina, o mercado de automóveis dos EUA e de suas filiais em outros países cedia participação de mercado para os produtos da indústria japonesa. Esta, graças à maior competitividade de seus produtos (menor preço e menor consumo de combustível por $\mathrm{km}^{8}$ ) pode avançar com seus produtos.

Como se sabe, o cluster automotivo dos EUA, além de ter sido um dos pólos econômicos fundamentais do desenvolvimento daquele país ao longo de todo o século XX, é também uma forte expressão simbólica dos valores da liberdade e do individualismo tão valorizados pela

diferenças entre as formas de produção da indústria automobilística Ocidental e a japonesa, leia-se o excelente trabalho de Womack (1992). 
propaganda do "American Way of Life". Logo as implicações desta "invasão" por parte de um ex-inimigo que se supunha derrotado na 2.a Guerra não se restringiram à economia e impregnaram a propaganda, a política e também a vida acadêmica. Aí está, portanto, a origem do interesse de Harvard por conhecer as singularidades das empresas japonesas mencionados anteriormente. É relevante notar que o texto de 1986 que deu origem ao livro resenhado denominava-se " $\mathrm{O}$ novo jogo do desenvolvimento de novos produtos" sugerindo que, numa primeira abordagem sobre as singularidades das empresas japonesas, a temática do Conhecimento não se encontrava ainda no primeiro plano que viria a ocupar posteriormente.

Pode-se, portanto, concluir que, curiosamente, o livro que catalisou a GC tinha na sua origem e motivação maiores preocupações com a inovação e o desenvolvimento de novos produtos que com o Conhecimento propriamente dito.

Para entender porque o Conhecimento veio a ter papel de destaque que adquiriu devemos examinar outros dois processos inter-relacionados que impulsionaram esta temática para o primeiro plano: um está relacionado à evolução no uso dos computadores e o outro ao crescimento da importância econômica do que se deu de chamar em propriedade intelectual.

\section{Evolução da Tecnologia da Informação e "Propriedade Intelectual"}

Em meados dos anos 1940, quando a multidão de futuros computadores não passava ainda de uns poucos experimentos eletromecânicos, já havia quem conceituasse "Máquinas de Pensar"9 como algo que iria

${ }^{9}$ Bush, Vannevar.As you may think.1945.

${ }^{10}$ Crawford S, The origin and development of a concept: the information society. Bulletin of the ocorrer no futuro visível. No início da década de 1950, os computadores se transformaram em gigantescos dispositivos eletrônicos e começaram a ser vendidos para grandes instituições. Foram apresentados à sociedade como "Cérebros Eletrônicos". Vê-se, pois que a associação entre computadores, inteligência e conhecimento vem de tempos atrás.

Ao longo das décadas subseqüentes os computadores se transformam no núcleo de um novo e cada vez mais importante ramo da divisão social do trabalho que passa de uma subdivisão de "Fabricante de Equipamentos para Escritório" a setor de "Processamento de Dados" e daí a "Tecnologia de Informação". Na década de 1950 e 1960 o sub-setor praticamente se resumia a sete grandes fabricantes de computadores liderados pela IBM. Conforme o processo evolui diferencia-se a fabricação (equipamentos, partes, peças e componentes) e a prestação de serviços (desenvolvimento de software, treinamento, assistência técnica, consultoria, entre outros). À medida que a quantidade destes novos artefatos vai se multiplicando, amplia-se a variedade de aplicações em que foram sendo empregados e sua presença na sociedade se torna cada vez mais perceptível. Não tarda para que o fenômeno como um todo constituísse uma base auto-evidente para generalizações do tipo "Sociedade da Informação" e "Sociedade do Conhecimento"10.

Registre-se, também, a existência de uma circularidade simbiótica e que se retroalimenta entre os setores científicos e acadêmicos, a imprensa e o mundo corporativoi: se algum destes segmentos afirma que foi desenvolvida uma "Tecnologia da Informação" pode-se daí derivar e generalizar uma "Sociedade da Informação".

Medical Library Association. 1983 October; 71(4)380 (online em http://www.ncbi.nlm.nih.gov/pmc/ articles/PMC227258). 
E vice-versa: se vivemos numa "Sociedade da Informação" podemos daí concluir que há uma "Tecnologia (ou tecnologias) da Informação". Mutatis mutandis, esta circularidade atuou também com o "Conhecimento". Nas palavras de Nonaka "Qualquer gerente que leia jornais e revistas não especializados perceberá que entramos na "sociedade do conhecimento" na qual o conhecimento não é apenas outro recurso, ao lado dos fatores de produção tradicional terra, capital e trabalho - mas sim o recurso mais importante" (Nonaka, 1995, p.264). Não surpreende, portanto que em sincronia com o advento da Internet e da Web 1.0 $0^{11}$ bem como com outras ferramentas relacionadas à Tecnologia da Informação, o tema da GC aparecesse no primeiro plano dos radares dos assuntos acadêmicos relevantes.

\section{Ferramentas de Tecnologia de Informação e a Gestão do Conhecimento}

Em 1989, o advento da Web 1.0 com sua interface de apontar e clicar nos links azuis, operacionalizada mediante um conjunto de protocolos entre os quais se destaca o HTTP (Hyper Text Transfer Protocol), abriu as portas da Internet para multidões de leigos. A facilidade e velocidade com que os nascentes mecanismos de busca colocavam a disposição dos leigos informações antes inacessíveis fez amadurecer na sociedade a percepção de que a qualificação "do conhecimento" era algo natural e que a necessidade do Gerenciamento do Conhecimento passasse a ser algo relevante e auto-evidente. Entendese, portanto, porque o foco inicial do artigo

${ }^{11}$ Berner-Lee, T., "British physicist Tim BernersLee invented the World Wide Web at CERN" in 1989. http://info.cern.ch/

${ }^{12} \mathrm{Um}$ exemplo sempre citado e que aparentemente não passa de uma "lenda urbana" seria o caso do WalMart que usando estas técnicas teria se surpreendido com a alta frequiência até então não percebida do aumento simultâneo das vendas de de Nonaka (1986) tenha se deslocado do "novo jogo do desenvolvimento de novos produtos" para um livro em que a "Criação de Conhecimento" estivesse em destaque já no título e que o mesmo tenha podido exercer o efeito catalisador a que já nos referimos. Vemos aqui, também, onde foi que Nonaka buscou o termo "hipertexto" para batizar a organização que aliaria as virtudes $\mathrm{da}$ burocracia e da força-tarefa.

Em 1989 deu-se também o lançamento comercial da 1.a versão do Lotus Notes um software revolucionário estruturado para a colaboração que integrava correios eletrônicos, agendas e possibilidades de desenvolvimento de bases de dados para trabalhos em grupo. A ampla disponibilização de bases de dados não estruturadas que podiam ser indexadas e pesquisadas era um progresso em relação às bases de dados estruturados que já contavam com estes recursos e que existiam desde muito antes.

As bases de dados estruturadas tinham dado origem às práticas de Data Mining e Data Warehouse (ou seja, à constituição de armazéns de dados e sua mineração) com o objetivo de extrair novos conhecimentos a fim de identificar relações que até então não tinham sido percebidas. Isto seria depois incorporado às práticas de KM sob o nome de Business Intelligence ${ }^{12}$. $\mathrm{Na}$ atualidade quando cresce o interesse por descobrir novas relações a partir de quantidades googolianas ${ }^{13} \mathrm{de}$ informações disponíveis na Internet e, em especial, nas redes sociais, esta atividade está sendo denominada de Big Data.

No ambiente do Lotus Notes - mesmo antes de ser harmonicamente integrado à

fraldas e cervejas em dias próximos aos fins de semana. Ao pesquisar descobriu que os compradores eram pais com bebes pequenos se abastecendo para o fim de semana. Como resultado passou a colocar os dois itens próximos e com esta ação teria aumentado a venda de ambos.

131 googol é o número 1 seguido de 100 zeros. É deste termo que o Google tirou sua denominação. 
Internet - reproduziram-se de forma melhorada recursos já disponíveis na Internet $^{14}$ e, também, desenvolveram-se novas ferramentas de TI.

Entre elas:

- um Gerenciador de Documentos (Domino.Doc que permitia à organização automatizar fluxos, controlar versões, monitorar acessos, indexar e recuperar conteúdos, entre outras características). Muitas outras empresas desenvolveram gerenciadores de documentos. De interesse para a GC foi sua evolução em repositórios de informação pesquisáveis em favor da produção de conhecimentos;

- E-Learning que possibilitava a criação e realização de cursos a distância, fazendo assim parte de um tema permanente da GC que é o da Educação à Distância $(\mathrm{EaD})$;

- o mais importante de todos, o Projeto Raven ${ }^{15}$, um protótipo de ferramenta de KM usado também pelo Estado Maior das Forças Conjuntas dos EUA que chegou a ser visto como a própria encarnação do que seria Knowledege Management. Seu escopo consistia em relacionar

\footnotetext{
${ }^{14}$ Por exemplo os Grupos de Interesse (Usenet) que depois seriam incorporadas ao conceito de Comunidades de Prática como um dos elementos que fariam parte de um ambiente onde o Conhecimento é gerenciado. No ambiente Notes era possível configurar o sistema para ao se consultar uma base específica, saber-se se determinado especialista estava online e com ele interagir.

15 ""Raven" is the project codename for a collection of knowledge management technologies. The

"Raven" development effort includes a knowledge
}

"pessoas, lugares e coisas", facilitar a constituição de forçastarefa, bem como favorecer o controle das atividades em curso na organização. Avaliava-se que estas soluções teriam grande demanda e potencial de aplicação nas mega-corporações.

- tem aqui também sua origem a febre de "portais de conhecimento", WebSites que se constituíram numa das ferramentas em que se encarnava o $\mathrm{KM}$ ao criar nas grandes organizações um único ponto de acesso a partir do qual seus integrantes poderiam encontrar as informações que necessitavam.

Relacionado à gestão de pessoas foram se incorporar aos temas de GC, as ferramentas de Tecnologia de Informação para o mapeamento de competências dando origem a aplicações como o Banco de Talentos corporativos e a avaliação da disponibilidade no futuro de competências demandadas pelas corporações, entre outras.

$\mathrm{O}$ autor assinala que ao se lançar, por volta de 1995, o conceito guarda-chuva do GC, diversos conceitos, idéias e ferramentas, oriundos da Internet, da Tecnologia de Informação e de outras áreas vieram ali se abrigar. Respondeu o conceito de intangível que surgiu nas empresas especializadas no desenvolvimento software na década de

portal, K-station, to manage personal and community information and activity and Discovery Server for search and navigation, content tracking and analysis, user profiling and expertise location. "Raven" offerings are a key element of Lotus' overall knowledge management strategy, which includes services, methodologies and solutions from Lotus and IBM, all captured under the unifying theme of "People, Places \& Things."' in Lotus \& IBM Knowledge Management Strategy. 
$1970^{16}$. Com o advento da microinformática, a produção autônoma de software aumentou ainda mais sua importância e visibilidade, assim como os processos envolvendo licenciamentos e direitos de cópia e reprodução ${ }^{17}$.

$\mathrm{Na}$ mesma dimensão em que cresce a importância do software, também a "pirataria" torna-se a arena mais visível de enfrentamento entre (e intra) corporações, países e populações em torno do que se dará em chamar de propriedade intelectual. Como esperamos mostrar a seguir, uma série de questões agrupadas sob a denominação de propriedade intelectual irá se constituir em objeto de estudo e de interesse da GC.

\section{Gestão do Conhecimento e "Propriedade Intelectual"}

No modo capitalista de produção a maximização do lucro é o que move as empresas. É isto que faz com que seja tão impetuosa a busca por inovações. Quando as inovações resultam em novos produtos isto gera rendimentos extraordinários. Quando as inovações resultam em processos mais eficientes então, mantidos constantes os preços de mercado, a empresa vê sua rentabilidade aumentar na mesma proporção em que se reduzem os custos. De forma simples e sintética, este é o pano de fundo que explica $\mathrm{O}$ frenesi contemporâneo pelas inovações e contextualiza o GC.

À medida que o dinamismo econômico geral é dado pelo fluxo de inovações ocorre uma mudança no perfil de como é usada a força de trabalho. Diminui a demanda de suas capacidades musculares e mecânicas

${ }^{16}$ Expressivo exemplo foi a SAP constituída em 1972 na Alemanha que viria a se tornar a maior e mais importante desenvolvedora de software para gestão do mundo.

17 A Microsoft é o caso mais notório de empresa que se especializa no desenvolvimento de software para substituídas que são pelo uso de máquinas. Estas fazem o trabalho pesado e repetitivo. Em contrapartida aumenta a demanda de outras capacidades, habilidades e atitudes da força de trabalho. Podemos nos referir a isto como a um aumento da densidade espiritual e intelectual do processo produtivo. É o que ocorre na dinâmica econômica do 2 .o pósguerra a partir das empresas dos EUA e é imitado pelas concorrentes de outros países.

Do ponto de vista dos valores econômicos envolvidos, a parcela do custo direto dos produtos (dos elementos necessários à produção de cada unidade individual, como por exemplo, matériasprimas diretas) é cada vez menor ${ }^{18}$ enquanto aumentam as porcentagens referentes a outras etapas do processo como Pesquisa \& Desenvolvimento, Distribuição, Propaganda e Marketing.

O aumento da dimensão intelectual na produção mercantil inicialmente é pouco evidente nos novos setores e produtos que surgem no 2.o pós-guerra. Os programas dos computadores (software) aparecem como complementos ou apêndices do hardware. $\mathrm{O}$ mesmo ocorre com músicas, filmes, séries de TV, e toda uma gama de produtos antes inexistentes ou pouco significativos. Neles não se distinguem conteúdos dos suportes físicos e de outros dispositivos necessários ao seu consumo. $\mathrm{Na}$ eletroeletrônica esta percepção vai mudando a partir da década de 1980 quando se difundem a microinformática e a microeletrônica. A partir de então parece não haver atividade que não tenha sido redefinida pela introdução destas novas tecnologias. Também, a Internet vai se tornando onipresente a partir de meados da década de 1990 e tornam-se disponíveis

microcomputadores e é apenas um caso entre dezenas de milhares

${ }^{18}$ Isto corresponde ao que Marx descreveu no livro terceiro de "O Capital - Crítica da Economia Política" à tendência para o aumento da composição organiza do capital. 
novos dispositivos para usufruir os conteúdos.

Surgem novos setores e novos produtos, como por exemplo, a biotecnologia que cria organismos naturais geneticamente modificados para os quais as empresas reivindicam patentes. Ou ainda a produção de fármacos cujos diretos são irrisórios mas precisam amortizar grandes valores resultantes de processo de pesquisa e da ansiedade corporativa por rentabilidade. Mesmo em setores tidos como tradicionais como, por exemplo, vestuário, móveis e produção de alimentos aumenta a densidade intelectual e espiritual do processo de trabalho não só pela utilização de novos materiais e novas tecnologias mas pela intensificação do uso do design empregado com múltiplos objetivos que vão da economia de recursos no processo de produção a melhorias na embalagem, transporte, processos de armazenamento até sua diferenciação mercadológica pelo uso inteligente da estética ${ }^{19}$.

$\mathrm{Na}$ razão direta do crescimento da densidade intelectual dos processos econômicos crescem também os conflitos de apropriação. A quem pertence a criação ? Ao autor? Ou à empresa que o contratou como funcionário ou prestador de serviço? Os conflitos de apropriação ocorrem ao longo de

19 O fenômeno do aumento da densidade intelectual na produção mercantil está na base da valorização de atividades que envolvem o design industrial, a moda e a culinária e o que se deu em chamar de soft industries ou economia criativa.

http://pt.wikipedia.org/wiki/Economia_criativa. "são 13 os setores da Economia Criativa:: Arquitetura, Publicidade, Design, Artes, Antiguidades, Artesanato, Moda, Cinema e Vídeo, Televisão, Editoração e Publicações, Artes Cênicas (Performing Arts), Rádio, Softwares de lazer, Música”.

${ }^{20} \mathrm{O}$ nome das empresas ligadas a Tecnologia da Informa;'ao como Apple, Oracle, Microsoft, IBM, Samsung, LG, Google, entre muitas outras, aparecem relacionadas com freqüência cada vez maior a litígios jurídicos com acusações mutuas e recíprocas por uso indevido de patentes ao ponto de que tais litígios envolvendo valores bilionários tornaram-se em si mesmos arma de conquista e defesa de mercados toda a cadeia de valor composta por autores e criadores do intangível, seus representantes e distribuidores comerciais, os fabricantes de hardware que são o suporte material do intangível ou dos dispositivos necessários para que possam ser usufruídos pelos usuários finais, assim como os usuários finais propriamente ditos. Além dos conflitos pela apropriação surgem as assim consideradas transgressões: imitações, cópias, utilização indevida de métodos, processos, idéias, conceitos, algoritmos e assim por diante que ganham dimensões econômicas, geográficas e sociais nunca antes vistas na História20. Também tem início a ocorrência de fenômenos inéditos como por exemplo as crescentes restrições para o acesso amplo do público a bibliotecas e textos especializados ou a cobrança de significativos valores para acesso aos mesmos ${ }^{21}$.

Um indicativo do crescimento destes conflitos pode ser percebido na própria necessidade de criação em 1967 da WIPO (World Intellectual Property Organization, ou Organização Mundial da Propriedade Intelectual) nos marcos da ONU. Outro evento ainda mais expressivo deste processo foi a culminação em 1994 da Rodada Uruguay do GATT que resultou na criação da Organização Mundial do Comércio e, neste contexto, do estabelecimento do TRIPS

umas perante as outras e todas contra novos entrantes nestes mercados que não tenhmam condições econômicas e "tecnológicas" para a realização de enfrentamentos longos e dispendiosos. 21 “"'Há um turbilhão acontecendo fora do Brasil na área de editoração científica”. O autor desta afirmação irrefutável é Benedito Barraviera, presidente da Associação Brasileira de Editores Científicos (ABEC). O "turbilhão" se refere ao movimento feroz e de amplitude viral que está ocorrendo no meio acadêmico internacional em defesa ao acesso aberto à informação científica produzida com financiamento público, porém publicada por editoras privadas em periódicos científicos com preços exorbitantes." in Kämpf , C.. Acesso aberto ao conhecimento científico tem apoio crescente de cientistas, ComCiencia, 10/06/2012 
(Agreement on Trade Related Aspects of Intellectual Property Rights ou Acordo sobre os Direitos Comerciais Relacionados à Propriedade Intelectual) ${ }^{22}$.

As dimensões econômicas do acima exposto adquirem tal vulto que as entidades de contadores e auditores passam a ser envolvidas nas discussões de como relacionar e valorizar os Ativos Intangíveis para efeito da elaboração de Balanços e Demonstrações Contábeis, os governos se interessam sobre sua taxação e se interessam em saber como se justificam para efeito de remessas internacionais de valores.

Com o que foi exposto nos parágrafos anteriores explica-se porque as questões ligadas a patentes, direitos autorais, proteção de marca, entre outras, relacionadas ao que se deu de chamar em "Propriedade Intelectual"23 são objeto de crescente interesse social e vão integrar-se ao objeto de estudo da Gestão do Conhecimento.

\section{Considerações Finais}

Gerenciamento do Conhecimento é uma expressão que teve origem na atividade acadêmico-corporativo enfocada no processo de inovação e criou um novo campo de pesquisas. Este campo hoje é composto pela intersecção do estudo dos processos de

\footnotetext{
${ }^{22}$ Entre os acordos criados pela institucionalidade resultante da 2.a Guerra Mundial, em 1947, esteve o GATT (General Agreement on Tariffs and Trade, ou Acordo Geral sobre Tarifas e Comércio). Seu objetivo precípuo era prevenir que o ambiente de aguda competição comercial que contribuiu para o surgimento da 2.a Guerra voltasse a surgir. A partir de 1994, as reuniões do GAT'T deram lugar à Organização Mundial do Comércio (OMC) como instituição multilateral onde conflitos comerciais entre países eram discutidos e, às vezes, resolvidos. A necessidade de um organismo multilateral onde se dirimam as controvérsias comerciais é, por si mesma, tão evidente que em 1994, 123 países participantes da Rodada Uruguay do GATT concordaram em constituir a OMC (Organização Mundial do
}

ensino e aprendizagem, do desenvolvimento organizacional com o objetivo de desenvolvimento de novos produtos e processos, da utilização de ferramentas de Tecnologia de Informação, de temas relacionados à "Propriedade Intelectual", dos processos de valorização e contabilização de ativos intangíveis, entre outros.

Como interessado no assunto a impressão é a de que depois de uma evolução impetuosa e crescimento acelerado até o início do milênio o tema encontra-se em fase de crescimento vegetativo. São ministradas disciplinas sobre o assunto, sobretudo em pós-graduações, as sociedades que congregam consultores, acadêmicos e profissionais interessados mantém-se ativas mas sem a vibração dos tempos de outrora. Esta sensação impressionista é também confirmada por uma pesquisa no Google Trends em que aparentemente o interesse pro "Knowledge Management" vem declinando. Trata-se de um paradoxo, pois se a demanda por inovação e conhecimento está claramente em ascenso porque o GC não o estaria também?

A título de contribuição para a discussão, a hipótese de que Gerenciamento do Conhecimento, tal como é praticada e ensinada hoje, padece de estreiteza de foco ao se limitar ao apoio aos processos de inovação nas corporações empresariais deixando de

Comércio). Dentre os documentos que resultaram na OMC estava o supracitado TRIPS que trouxe para o proscênio questões relacionadas à propriedade intelectual.

23 "Virou moda atirar copyright, patentes e marcas — três entidades separadas e diferentes envolvendo três conjuntos de leis separados e diferentes dentro da mesma panela e chamar isso de "Propriedade Intelectual". O termo distorcido e confuso não surgiu por acidente. Companhias que lucram com a confusão o promovem. E o meio mais claro para sair da confusão é rejeitar inteiramente o termo.", Stallman, Richard. Did you say "Intellectual Property"? 
atentar para todos os agentes externos á corporação que para isto contribuem e são também os beneficiários.

\section{Referências Bibliográficas}

1. BERNER-Lee, T., "British physicist Tim Berners-Lee invented the World Wide Web at CERN" in 1989. http:/ / info.cern.ch.

2. BUSH, Vannevar. As We May Think. The Atlantic Monthly Digital Edition.1945. http://www.theatlantic.com/unboundflashb ks/computer/bushf.htm.

3. CRAWFORD $\mathrm{S}$, The origin and development of a concept: the information society. Bulletin of the Medical Library Association. 1983 October; 71(4)380 (online em http://www.ncbi.nlm. nih.gov/ pmc/articles/PMC227258).

4. HOUAISS, Antonio. Grande Dicionário Houaiss da Língua Portuguesa. 2009. http://houaiss.uol.com.br.

5. DRUCKER, Peter. Landmarks of Tomorrow. New York: Harper \& Row, 1957.

6. LOTUS. Lotus \& IBM Knowledge Management Strategy, 2001.

7. MACHLUP, F. The Production and Distribution of Knowledge in the United States, 1962.
8. MARX, Karl. O Capital - Crítica da Economia Política.

9. NONAKA, I., Takeuchi, H.. The Knowledge-Creating Company: How Japanese Companies Create the Dynamics of Innovation. Oxford University Press, 1995. 10. NONAKA, I., Takeuchi, H.. Criação de Conhecimento na Empresa: como as empresas japonesas geram a dinâmica da inovação. Elsevier, 1997 (20.a reimpressão).

11. SCHARMER, O.C.. Hypertext organization - Conversation with Ikujiro Nonaka Ikujiro Nonaka interview, in Reflections, Vol.2 N.2, 2001. http://www.slideshare.net/jonker1/ hypertext-organization-ikujiro-nonakainterview.

12. STALLMAN, Richard. Did you say "Intellectual Property"? http://www.gnu.org/philosophy/ notipr.en.html\#content.

13. REGENSTEINER, R.J.. As Modas na Administração de Empresas e o novo figurino do Gerenciamento do Conhecimento. www.interpsic.com.br. 2001. 14. TAYLOR, Frederick Winslow. The Principles of Scientific Management. 1911. 15. WOMACK, James P. A máquina que mudou o mundo. RJ, Campus, 1992. 